\title{
Amperometric NO gas sensor in the presence of diffusion barrier: selectivity, mass transfer of $\mathrm{NO}$ and effect of temperature
}

\author{
Jing-Shan Do ${ }^{\mathrm{a},{ }^{*}}$, Kanq-Jiuan $\mathrm{Wu}^{\mathrm{a}}$, Ming-Liao Tsai ${ }^{\mathrm{b}}$ \\ ${ }^{a}$ Department of Chemical Engineering, Tunghai University, Taichung 40704, Taiwan, ROC \\ ${ }^{\mathrm{b}}$ Department of Chemical Engineering, National Chin-Yi Institute of Technology, Taichung 411, Taiwan, ROC
}

Received 26 July 2001; received in revised form 20 February 2002; accepted 1 March 2002

\begin{abstract}
Using various PTFE films as diffusion barriers, the mass transfer of nitric oxide and the selectivity in the amperometric NO gas sensor is

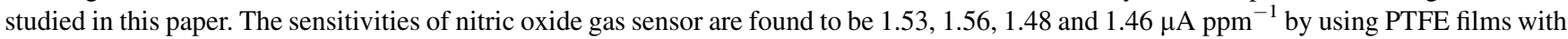
pore sizes of $0.2,1.0,5.0$ and $10.0 \mu \mathrm{m}$ as diffusion barriers, respectively, for gas flow rate greater than $160 \mathrm{ml} \mathrm{min}{ }^{-1}$. The diffusion coefficients of nitric oxide in PTFE diffusion barrier with pore size of $0.2,1.0,5.0$ and $10.0 \mu \mathrm{m}$ are found to be $8.57 \times 10^{-6}, 1.00 \times 10^{-5}$, $1.33 \times 10^{-5}$ and $1.45 \times 10^{-5} \mathrm{~cm}^{2} \mathrm{~s}^{-1}$, respectively. The mixing of Knudsen and bulk diffusions is found in the diffusion barrier with $1.0,5.0$ and $10.0 \mu \mathrm{m}$ pore size and the diffusion of nitric oxide in $0.2 \mu \mathrm{m}$ pore size of diffusion barrier is mainly contributed by Knudsen diffusion. The sensing current of $\mathrm{NO}$ gas sensor is significantly affected by the presence of $\mathrm{NO}_{2}$ and $\mathrm{SO}_{2}$. On the other hand, the interference from the humidity, $\mathrm{O}_{2}$ and $\mathrm{CO}$ in the $\mathrm{NO}$ gas sensor is insignificant.
\end{abstract}

(C) 2002 Elsevier Science B.V. All rights reserved.

Keywords: Amperometric NO gas sensor; Au/Nafion ${ }^{\circledR}$; Diffusion barrier; Mass transfer; Selectivity

\section{Introduction}

Nitric oxide produced from the combustion processes reacts with ozone in the atmosphere to form nitrogen dioxide. Nitric oxide and nitrogen dioxide combine with water in the atmosphere to become nitrous and nitric acids, which are one of the factors that cause the acid rains. Hence, it is very important for the environmental conservation to monitor the level of nitric oxide in the atmosphere. The chemiluminescene method [1] and electrochemical sensors [2-17] can monitor the concentration of nitric oxide in the gas phase.

Three types of electrochemical methods are used to monitor the concentration of nitric oxide: the conductimetric $[2,3,15]$, potentiometric $[4,15]$ and amperometric [5-17] gas sensors. Au/solid polymer electrolyte (Au/SPE) prepared by the chemical plating method is used as a working electrode for assembling the amperometric nitric oxide gas sensor [16]. The characteristics of Au/SPE and the sensing behavior of amperometric nitric oxide are systematically studied [17]. The anodic oxidation of nitric oxide on Au/Nafion ${ }^{\mathbb{R}}$ is first

\footnotetext{
${ }^{*}$ Corresponding author. Tel.: +886-4-23590262x114; fax: 886-4-23590009.

E-mail address: jsdo@mail.thu.edu.tw (J.-S. Do).
}

order with respect to nitric oxide [17]. The diffusivity of nitric oxide and the equivalent diffusion layer thickness within the porous electrode are evaluated to be $3.43 \times$ $10^{-4} \mathrm{~cm}^{2} \mathrm{~s}^{-1}$ and $0.0513 \mathrm{~cm}$, respectively [17].

In general, the mass transfer resistance of electroactive species from bulk phase to the electrode surface in the presence of diffusion barrier is greater than that in the absence of diffusion barrier. Hence, the diffusion barriers are generally used to reduce the effect of the gas flow rate on the sensitivity of amperometric gas sensor. It is very important to study the mass transfer characteristics and the sensing behaviors of an amperometric gas sensor in the presence of diffusion barrier.

Furthermore, the selectivity is one of the main problems in the practical application of the gas sensors. The selectivity of the nitric oxide electrochemical sensors is seldom discussed in detail. It is very interesting to understand the interference of the amperometric nitric oxide gas sensor from the other gases, such as sulfur dioxide, carbon monoxide, oxygen, nitrogen dioxide.

The characteristics of the mass transfer of nitric oxide through gas diffusion layer, diffusion barrier and porous electrode in the presence of various thickness and pore size of PTFE films are studied in this paper. The selectivity and the effect of temperature on the mass transfer of nitric oxide in the amperometric nitric oxide gas sensor are also investigated. 


\section{Experimental}

\subsection{Preparation of $\mathrm{Au} / \mathrm{Nafion}^{\circledR}$}

Gold was deposited on Nafion ${ }^{\circledR}(117)$ by TakenakaTorikai (T-T) chemical plating method $[16,17]$. The loading of $\mathrm{Au}$ and the electroactive area of Au/Nafion ${ }^{\circledR}$ were discussed elsewhere [16-18]. The PTFE films with pore sizes of $0.2 \mu \mathrm{m}$ (Advantec MFS, SIERAA CD65), $1.0 \mu \mathrm{m}$ (MSI, WESTBORO 82291), $5.0 \mu \mathrm{m}$ (MSI, WESTBORO 76121) and $10.0 \mu \mathrm{m}$ (MSI, WESTBORO 83634) were used as diffusion barriers covered on the working electrode $(\mathrm{Au} /$ Nafion ${ }^{\circledR}$ ). The grid (polypropylene based) was used to support the PTFE films with pore size of 0.2 and $1.0 \mu \mathrm{m}$. On the other hand, the support for PTFE films with pore size of 5.0 and $10.0 \mu \mathrm{m}$ were not used in this paper. Nitrogen gas $(99.99 \%)$ was used as carrier gas in the amperometric NO gas sensor.

\subsection{Anodic oxidation of nitric oxide}

$\mathrm{Au} / \mathrm{Nafion}{ }^{\circledR}$ prepared in this work was used as a working electrode and a separator in a divided cell. The counter chamber located on the backside of Au/Nafion ${ }^{\circledR}$ was filled with $0.5 \mathrm{M} \mathrm{H}_{2} \mathrm{SO}_{4}$ which was used as the proton and water source for ionic conduction through the Nafion ${ }^{\circledR}$ film. Platinum wire and $\mathrm{Ag} / \mathrm{AgCl} / 3 \mathrm{M} \mathrm{NaCl}$ aqueous solution were used as counter and reference electrodes, respectively. The test gases flowed into the working chamber and a gassolid reaction interface was formed on the working electrode $(\mathrm{Au})$. An Au O-ring, used as a current collector, was in contact with the working electrode. Two rubber O-ring were placed on either side of $\mathrm{Au} / \mathrm{Nafion}{ }^{\circledR}$ to prevent any leakage from the working and counter chambers. A massflow-rate controller (Sierra 902C) controlled the concentration of nitric oxide in the gas phase and the gas flow rate. The relationship between the current and potential was measured by using an electrochemical analyzer (BAS 100B).

The limiting current for anodic oxidation of nitric oxide was obtained by setting the potential of working electrode at $1.05 \mathrm{~V}$ (versus $\mathrm{Ag} / \mathrm{AgCl} / 3 \mathrm{M} \mathrm{NaCl}$ aqueous solution) [16].

\section{Theoretical analysis}

Three mass transfer resistances are found for transferring nitric oxide from the bulk phase to electroactive surface in the presence of diffusion barrier (Fig. 1). They are (1) the transfer resistance of nitric oxide from gas bulk phase to the diffusion barrier; (2) the resistance for transferring nitric oxide through the diffusion barrier; and (3) the mass transfer of nitric oxide within the porous electrode.

The concentration of nitric oxide in the bulk phase $\left(C^{*}\right)$ was decreased to $C^{\prime}$ when nitric oxide was diffused through the gas diffusion layer $\left(L_{\mathrm{g}}\right)$ to interface of the gas phase and

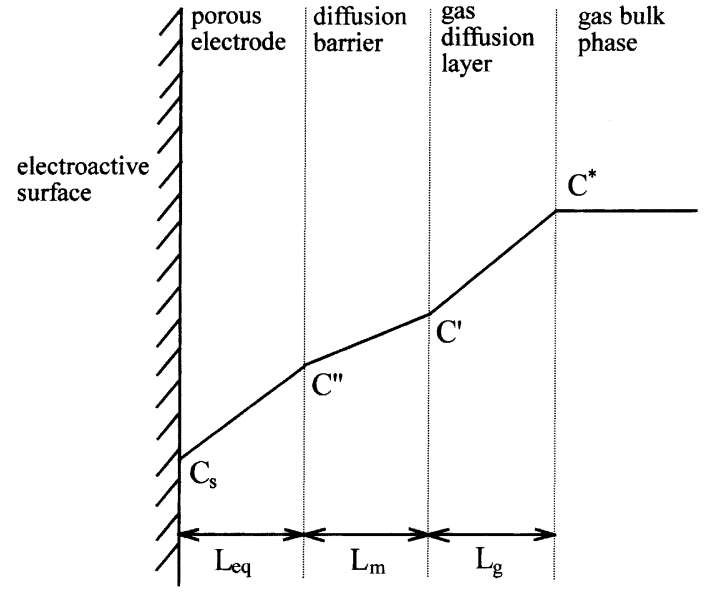

Fig. 1. Schematic representation of mass transfer of nitric oxide from the gas bulk phase to the electroactive surface.

the diffusion barrier. A PTFE film with thickness of $L_{\mathrm{m}}$ was placed on the top of porous electrode to serve as the diffusion barrier. The concentration of nitric oxide decreased to $C^{\prime \prime}$ while transferring nitric oxide to the surface of porous electrode through diffusion barrier. Nitric oxide was assumed to be oxidized at the electroactive surface located at the inside of the porous $\mathrm{Au}$ electrode with an equivalent thickness of $L_{\mathrm{eq}}$. The concentration of nitric oxide decreased from $C^{\prime \prime}$ to $C_{\mathrm{s}}$ when nitric oxide was transferred to the electroactive surface through the porous electrode.

When the limiting current $\left(I_{\mathrm{L}}\right)$ of anodic oxidation of nitric oxide is applied $\left(C_{\mathrm{s}} \sim 0\right)$, the mass flux of nitric oxide can be expressed as

$J_{\mathrm{NO}}=\frac{I_{\mathrm{L}}}{n F A}=\frac{D_{\mathrm{eq}}}{L_{\mathrm{eq}}} C^{\prime \prime}=\frac{D_{\mathrm{m}}}{L_{\mathrm{m}}}\left(C^{\prime}-C^{\prime \prime}\right)=\frac{D}{L_{\mathrm{g}}}\left(C^{*}-C^{\prime}\right)$

where $D_{\mathrm{m}}$ is the diffusivity of nitric oxide in the PTFE film. Solving Eq. (1), the concentrations of nitric oxide in the interface of the gas phase and the diffusion barrier $\left(C^{\prime}\right)$ as well as in the interface of the diffusion barrier and the electrode $\left(C^{\prime \prime}\right)$ are derived to be

$C^{\prime}=\frac{L_{\mathrm{m}} D\left(L_{\mathrm{m}} D_{\mathrm{eq}}+L_{\mathrm{eq}} D_{\mathrm{m}}\right)}{L_{\mathrm{g}} L_{\mathrm{m}} D_{\mathrm{eq}} D_{\mathrm{m}}+L_{\mathrm{m}}^{2} D_{\mathrm{eq}} D+L_{\mathrm{eq}} L_{\mathrm{m}} D_{\mathrm{m}} D} C^{*}$

$C^{\prime \prime}=\frac{L_{\mathrm{eq}} D_{\mathrm{m}}}{L_{\mathrm{m}} D_{\mathrm{eq}}+L_{\mathrm{eq}} D_{\mathrm{m}}} C^{\prime}$

In general, increasing the gas flow rate resulted in the decrease of the thickness of gas diffusion layer and the diffusion resistance [19-21]. Further increase of the gas flow rate was found to result in the diffusion resistance in gas diffusion layer becoming negligible. Then the concentration of nitric oxide in the interface of gas phase and diffusion barrier interface was found to be equal to that in the bulk phase $\left(C^{\prime}=C^{\prime \prime}\right)$. And the concentration of nitric oxide in the interface of the diffusion barrier and the electrode was 
derived from Eq. (3) to be

$C^{\prime \prime}=\frac{L_{\mathrm{eq}} D_{\mathrm{m}}}{L_{\mathrm{m}} D_{\mathrm{eq}}+L_{\mathrm{eq}} D_{\mathrm{m}}} C^{*}$

Substituting Eq. (4) into Eq. (1) yielded the expression for the limiting current as shown in the following equation,

$\frac{I_{\mathrm{L}}}{n F A}=\frac{D_{\mathrm{eq}}}{L_{\mathrm{eq}}} \frac{L_{\mathrm{eq}} D_{\mathrm{m}}}{L_{\mathrm{m}} D_{\mathrm{eq}}+L_{\mathrm{eq}} D_{\mathrm{m}}} C^{*}$

It is assumed that the mass transfer flux of nitric oxide from gas bulk phase to the electroactive surface is expressed in terms of the effective diffusivity $\left(D_{\text {eff }}\right)$ and diffusion layer thickness $\left(L_{\text {eff }}\right)$.

$J_{\mathrm{NO}}=\frac{I_{\mathrm{L}}}{n F A}=\frac{D_{\mathrm{eff}}}{L_{\mathrm{eff}}} C^{*}$

By comparing Eq. (5) with (6), the term $L_{\text {eff }} / D_{\text {eff }}$ was obtained to be,

$\frac{L_{\text {eff }}}{D_{\text {eff }}}=\frac{L_{\mathrm{m}}}{D_{\mathrm{m}}}+\frac{L_{\mathrm{eq}}}{D_{\mathrm{eq}}}$

\section{Results and discussion}

\subsection{Mass transfer of nitric oxide}

The thickness $\left(L_{\mathrm{g}}\right)$ and the mass transfer resistance in the gas diffusion layer decrease with the increase in the gas flow rate [19-21]. The anodic oxidation of nitric oxide on $\mathrm{Au} /$ Nafion ${ }^{\circledR}$ had occurred for the potential greater than $0.73 \mathrm{~V}$ and the limiting current was found for the potential greater than $0.95 \mathrm{~V}$ [16]. The relationships between the anodic current and the run time for the step change of the anodic potential from $0.45 \mathrm{~V}$ (no nitric oxide oxidation) to $1.05 \mathrm{~V}$ (limiting current of the anodic oxidation of nitric oxide) are indicated in Fig. 2. An increase in the gas flow rate resulted in the increase of the mass transfer rate. The limiting current of the anodic oxidation of nitric oxide hence increased with the gas flow rate. Further increase of the gas flow rate would make the mass transfer resistance in the gas diffusion layer negligible in comparison with the resistances within the diffusion barrier and/or the porous electrode. The limiting current of the anodic oxidation of nitric oxide was hence kept constant.

The current of anodic oxidation of nitric oxide decreased sharply in the initial state for switching the potential from 0.45 to $1.05 \mathrm{~V}$ (Fig. 2). The higher current in the initial state is due to the higher concentration of nitric oxide on the electroactive surface. If the run time is increased, the concentration of nitric oxide on the anodic surface decreases and the diffusion layer thickness increases. Therefore, the current of anodic oxidation of nitric oxide decreases with the run time. The current decays continuously in the absence of forced convection (gas flow rate $=0 \mathrm{ml} \mathrm{min}^{-1}$ ). On the

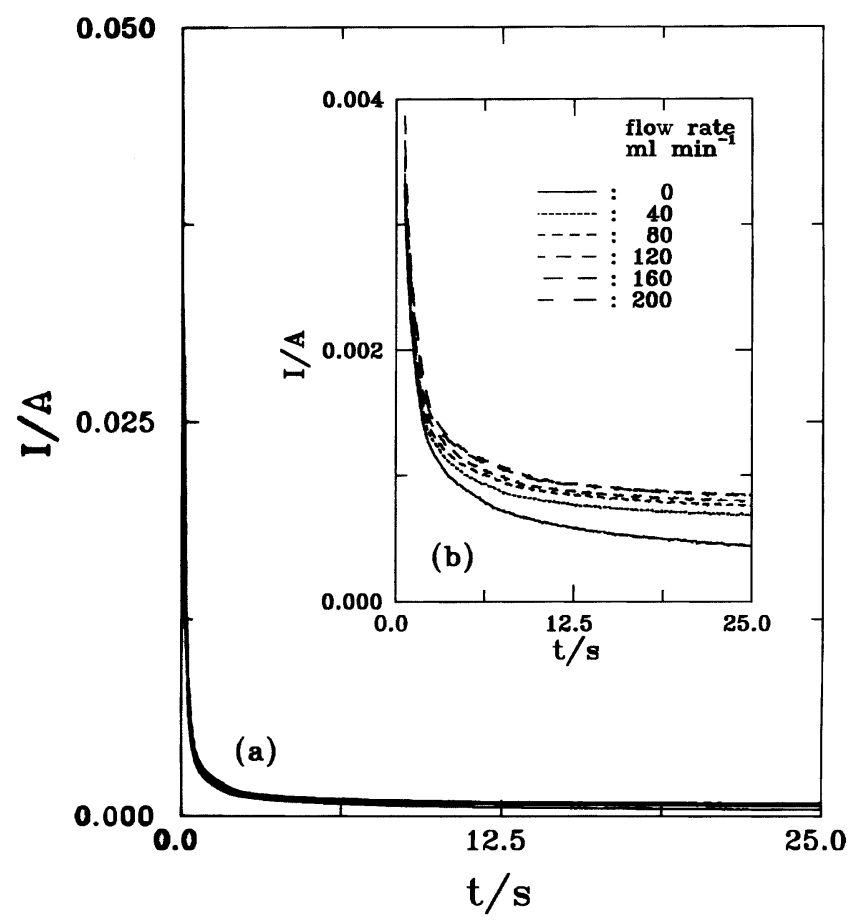

Fig. 2. Effect of run time on the current of anodic oxidation of nitric oxide. Potential step: $0.45 \rightarrow 1.05 \mathrm{~V},[\mathrm{NO}]=500 \mathrm{ppm}$, room temperature, working electrode: Au/Nafion ${ }^{\circledR}$ (geometric area $=0.5 \mathrm{~cm}^{2}, \mathrm{Au}$ loading $=7.5 \mathrm{mg} / \mathrm{cm}^{2}$ ), diffusion barrier: $0.2 \mu \mathrm{m}$ pore size of PTFE film.

other hand, the thickness of diffusion layer is ultimately limited to a fixed value and the current approaches a steadystate value in the presence of gas convection. Then the current versus run time can be characterized by the Cottrell equation [22].

$I=\frac{n F A C^{*} D_{\mathrm{eff}}^{1 / 2}}{(\pi t)^{1 / 2}}$

where $n, F, A$ and $D_{\text {eff }}$ are the electrons transferred in the anodic oxidation of nitric oxide, the faraday, the electroactive area and the effective diffusivity described in the theoretical section, respectively.

The linear relationships were obtained by plotting current against $t^{-1 / 2}$ for various gas flow rates as shown in Fig. 3. According to Eq. (8), the slopes in Fig. 3 are equal to the term of $n F A C^{*} D_{\text {eff }}^{1 / 2} \pi^{-1 / 2}$. The effective diffusivities $\left(D_{\text {eff }}\right)$ for various gas flow rates are calculated by substituting the values of $n, F, A, C^{*}$ and $\pi$ into the slopes in Fig. 3 as illustrated in the second column of Table 1 . The effective diffusivity decreased from $2.88 \times 10^{-4}$ to $2.61 \times 10^{-4} \mathrm{~cm}^{2} \mathrm{~s}^{-1}$ with the increase of the gas flow rate from 0 to $160 \mathrm{ml} \mathrm{min}^{-1}$ in the presence of PTFE film with $0.2 \mu \mathrm{m}$ pore size as diffusion barrier. The effective diffusivity is unchanged for further increase of the

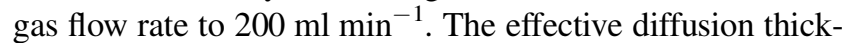
ness calculated based on Eq. (6) decreases from $5.70 \times 10^{-1}$ to $4.09 \times 10^{-1} \mathrm{~cm}$ with the increase of gas flow rate from 40 to $160 \mathrm{ml} \mathrm{min}^{-1}$ as shown in the last column of Table 1 . 


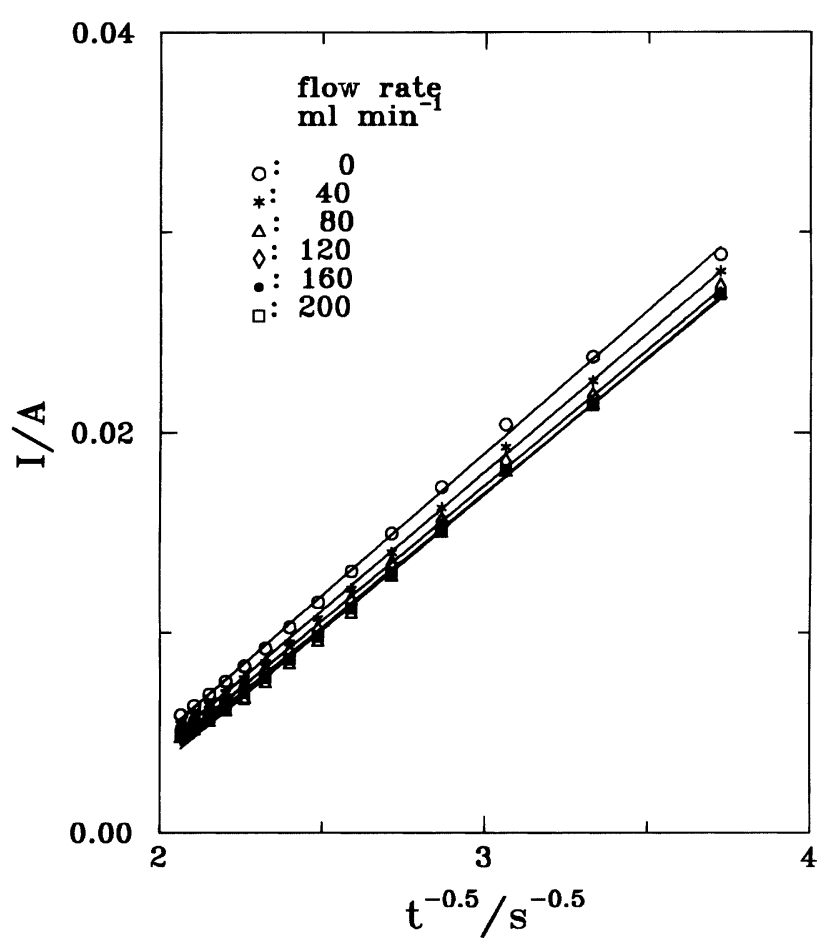

Fig. 3. Plot of $I$ vs. $t^{-0.5}$ for various gas flow rate. Potential step: $0.45 \rightarrow 1.05 \mathrm{~V},[\mathrm{NO}]=500 \mathrm{ppm}$, room temperature, working electrode: Au/Nafion ${ }^{\circledR} \quad$ (geometric area $=0.5 \mathrm{~cm}^{2}, \quad$ Au loading $=7.5 \mathrm{mg} / \mathrm{cm}^{2}$ ), diffusion barrier: $0.2 \mu \mathrm{m}$ pore size of PTFE film.

Similarly, the effective diffusion thickness changes slightly for the gas flow rate greater than $160 \mathrm{ml} \mathrm{min}^{-1}$. These experimental results indicate that the mass transfer resistance in the gas diffusion layer is negligible for the gas flow rate greater than $160 \mathrm{ml} \mathrm{min}^{-1}$.

When the mass transfer of nitric oxide in the gas diffusion layer is neglected, the effective diffusivity and thickness are expressed in Eq. (7). The equivalent diffusivity $\left(D_{\mathrm{eq}}\right)$ and thickness $\left(L_{\mathrm{eq}}\right)$ in the porous Au electrode have been evaluated in our previous work [14] to be $3.43 \times 10^{-4} \mathrm{~cm}^{2} \mathrm{~s}^{-1}$ and $0.051 \mathrm{~cm}$, respectively. The thickness of the PTFE film with $0.2 \mu \mathrm{m}$ pore size $\left(L_{\mathrm{m}}\right)$ shown in Table 2 is $0.012 \mathrm{~cm}$. The diffusivity in the PTFE diffusion barrier $(0.2 \mu \mathrm{m}$ pore size) $\left(D_{\mathrm{m}}\right)$ is evaluated to be $8.57 \times 10^{-6} \mathrm{~cm}^{2} \mathrm{~s}^{-1}$ by substituting $L_{\text {eq }}, D_{\text {eq }}$ and $L_{\mathrm{m}}$ in the Eq. (7) (Table 2).

Table 1

Effect of gas flow rate on the effective diffusivity and thickness

\begin{tabular}{cll}
\hline Gas flow rate $\left(\mathrm{ml} \mathrm{min}^{-1}\right)$ & $D_{\text {eff }} \times 10^{4}\left(\mathrm{~cm}^{2} \mathrm{~s}^{-1}\right)$ & $L_{\mathrm{eff}}(\mathrm{cm})$ \\
\hline 0 & 2.88 & - \\
40 & 2.76 & 0.570 \\
80 & 2.67 & 0.455 \\
120 & 2.64 & 0.436 \\
160 & 2.61 & 0.409 \\
200 & 2.60 & 0.403 \\
\hline
\end{tabular}

Potential step: $0.45 \rightarrow 1.05 \mathrm{~V}, \quad[\mathrm{NO}]=500 \mathrm{ppm}$, room temperature, working electrode: Au/Nafion ${ }^{\circledR}$ (geometric area $=0.5 \mathrm{~cm}^{2}, \mathrm{Au}$ loading $=7.5 \mathrm{mg} / \mathrm{cm}^{2}$ ), diffusion barrier: $0.2 \mu \mathrm{m}$ pore size PTFE film.
Table 2

The properties and diffusivities of the diffusion barriers

\begin{tabular}{llc}
\hline $\begin{array}{l}\text { Pore size of } \\
\text { PTFE film }(\mu \mathrm{m})\end{array}$ & $\begin{array}{l}\text { Thickness } \\
(\mu \mathrm{m})\end{array}$ & $\begin{array}{l}D_{\mathrm{m}} \times 10^{6} \\
\left(\mathrm{~cm}^{2} \mathrm{~s}^{-1}\right)\end{array}$ \\
\hline 0.2 & 120 & 8.57 \\
1.0 & 140 & 10.0 \\
5.0 & 190 & 13.3 \\
10.0 & 210 & 14.5 \\
\hline
\end{tabular}

The diffusivities of nitric oxide in the PTFE diffusion barriers with the various pore sizes obtained by the method described above are shown in Table 2. As the pore size of PTFE diffusion barrier was increased from 0.2 to $10.0 \mu \mathrm{m}$ the diffusivity of nitric oxide within the diffusion barrier increased from $8.57 \times 10^{-6}$ to $1.45 \times 10^{-5} \mathrm{~cm}^{2} \mathrm{~s}^{-1}$.

\subsection{Effect of diffusion barriers on the sensitivity and the response time of amperometric NO gas sensor}

The experimental results reveal that the gas flow rate for neglecting the mass transfer resistance in the gas diffusion layer are obtained to be $160,160,160$ and $120 \mathrm{ml} \mathrm{min}^{-1}$, respectively, when the PTFE films with 0.2, 1.0, 5.0 and $10.0 \mu \mathrm{m}$ are used as diffusion barriers. The sensitivity and the response time in the presence of various pore sizes and thickness of diffusion barriers for the gas flow rate equal to $200 \mathrm{ml} \mathrm{min}^{-1}$ are illustrated in Table 3. Decreasing the pore size of diffusion barrier results in the decrease of the sensitivity and the increase of the response time due to the increase of the diffusion resistance within the diffusion barrier. On the other hand, the sensitivity of NO gas sensor increases and the response time decreases with the decrease in the thickness of the diffusion barrier. As indicated in Table 2, the pore size of diffusion barrier used in this work decreases with the decrease of the thickness of the diffusion barrier. Accordingly, the mass transfer coefficient across the diffusion barrier $\left(D_{\mathrm{m}} / L_{\mathrm{m}}\right)$ changes slightly for the various pore size of diffusion barriers. Consequently, the sensitivity

Table 3

Effect of pore size and thickness of diffusion barrier on the sensitivity and response time of NO gas sensor

\begin{tabular}{lllll}
\hline $\begin{array}{l}\text { Pore size } \\
(\mu \mathrm{m})\end{array}$ & $\begin{array}{l}\text { Thickness } \\
(\mu \mathrm{m})\end{array}$ & $\begin{array}{l}D_{\mathrm{m}} / L_{\mathrm{m}} \\
\left(\mathrm{cm} \mathrm{s}^{-1}\right)\end{array}$ & $\begin{array}{l}\text { Sensitivity } \\
(\mu \mathrm{A})\end{array}$ & $\begin{array}{l}\text { Response } \\
\text { time }^{\mathrm{a}}(\mathrm{s})\end{array}$ \\
\hline 0.2 & 120 & $7.14 \times 10^{-4}$ & 1.53 & $33.6^{\mathrm{b}}$ \\
1.0 & 140 & $7.14 \times 10^{-4}$ & 1.56 & 29.0 \\
5.0 & 190 & $7.00 \times 10^{-4}$ & 1.48 & 39.1 \\
10.0 & 210 & $6.90 \times 10^{-4}$ & 1.46 & 39.2 \\
\hline
\end{tabular}

Applied potential $=1.05 \mathrm{~V}$, gas flow rate $=200 \mathrm{ml} \mathrm{min}^{-1}$, room temperature, $[\mathrm{NO}]=500 \mathrm{ppm}$, working electrode: Au/Nafion ${ }^{\circledR}$ (geometric area $=0.5 \mathrm{~cm}^{2}$, Au loading $=7.5 \mathrm{mg} / \mathrm{cm}^{2}$ ).

${ }^{a}$ The response time was defined as the time for $90 \%$ steady response current.

${ }^{\mathrm{b}}$ The response time of $\mathrm{NO}$ gas sensor in the presence of $0.2 \mu \mathrm{m}$ pore size PTFE film as diffusion barrier was evaluated in $400 \mathrm{ppm}$ NO. 


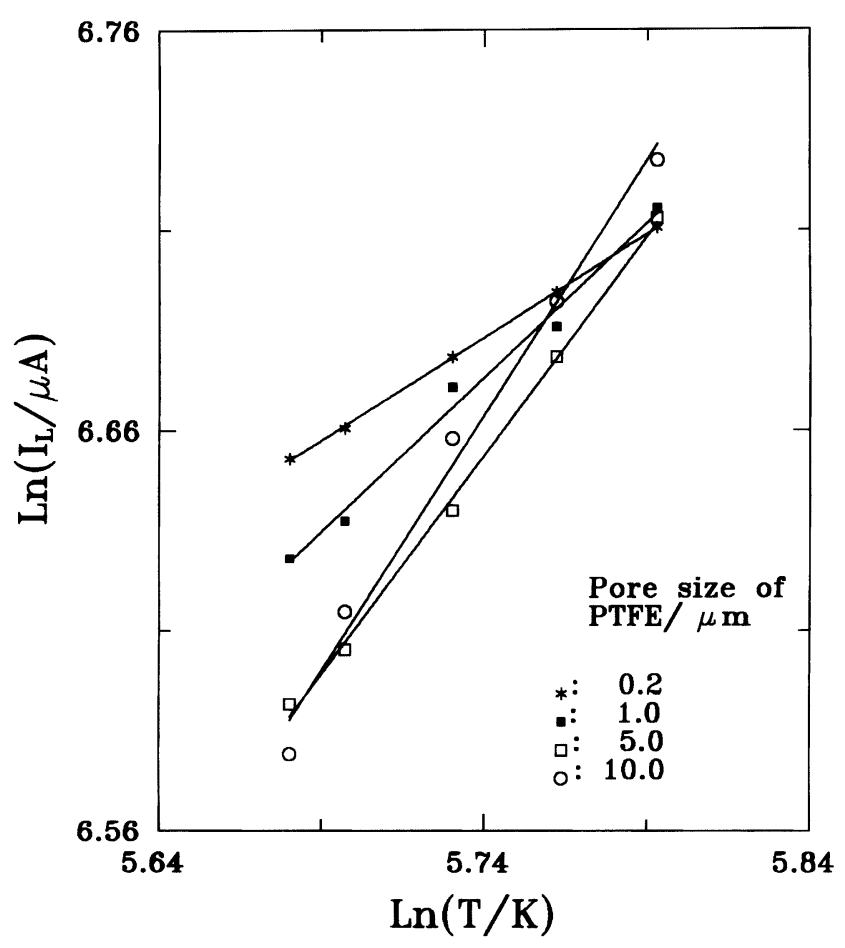

Fig. 4. Plot of $\ln \left(I_{\mathrm{L}}\right)$ vs. $\ln (T)$ for the various pore size of diffusion barriers. Applied potential: $1.05 \mathrm{~V},[\mathrm{NO}]=500 \mathrm{ppm}$, room temperature, gas flow rate $=200 \mathrm{ml} \mathrm{min}{ }^{-1}$, working electrode: Au/Nafion ${ }^{\circledR}$ (geometric area $=0.5 \mathrm{~cm}^{2}$, Au loading $=7.5 \mathrm{mg} / \mathrm{cm}^{2}$ ).

and the response time of NO gas sensor change insignificantly in the presence of various PTFE films as diffusion barriers (Table 3).

\subsection{Effect of temperature on the mass transfer}

The linear relationships of the logarithmic of limiting current of NO gas sensor and temperature were obtained in Fig. 4 for the various pore sizes of diffusion barrier. For example, in the presence of $0.2 \mu \mathrm{m}$ pore size of diffusion barrier, the limiting current of $\mathrm{NO}$ gas sensor increased from 775 to $821 \mu \mathrm{A}$ with the increase of temperature from 293 to $328 \mathrm{~K}$.

The term $D_{\text {eff }} / L_{\text {eff }}$ in Eq. (6) represents the mass transfer coefficient for transferring nitric oxide through the diffusion barrier and the porous electrode. On the other hand, the reciprocal of this term (i.e. $L_{\text {eff }} / D_{\text {eff }}$ in Eq. (7)) represents the diffusion resistance. The mass transfer resistance $\left(L_{\text {eff }} / D_{\text {eff }}\right)$ calculated from Table 1 for gas flow rate of $160 \mathrm{ml} \mathrm{min}^{-1}$ is equal to $1567 \mathrm{~s} \mathrm{~cm}^{-1}$. In our previous work, the mass transfer resistance within the porous electrode $\left(L_{\mathrm{eq}} / D_{\mathrm{eq}}\right)$ is found to be $149 \mathrm{~s} \mathrm{~cm}^{-1}$ [17]. Therefore, the mass transfer resistance in the diffusion barrier $(0.2 \mu \mathrm{m}$ pore size PTFE film) is calculated from Eq. (7) to be $1418 \mathrm{~s} \mathrm{~cm}^{-1}$. This result reveals that the mass transfer resistance is mainly dominated by the mass transfer within the diffusion barrier. Similar results are obtained for the various pore sizes of diffusion barriers.
The relationship of the bulk diffusivity and the temperature can be expressed as [23]

$\left(D_{\mathrm{NO}}\right)_{\mathrm{b}} \propto T^{3 / 2}$

and the Knudsen diffusivity is proportional to $T^{1 / 2}$ [23].

According to Eq. (6), the slope of $\ln I_{\mathrm{L}}$ against $\ln T$ is equivalent to the slope of $\ln D_{\text {eff }}\left(\sim \ln D_{\mathrm{m}}\right.$ based on the discussion in the above sections) versus $\ln T$. The slopes for the diffusion barriers with pore size of $0.2,1.0,5.0$ and $10.0 \mu \mathrm{m}$ were evaluated from Fig. 4 to be $0.51,0.76,1.09$ and 1.27 , respectively. The experimental results indicate that the diffusion of nitric oxide through diffusion barrier with $0.2 \mu \mathrm{m}$ pore size is mainly contributed from the Knudsen diffusion. On the other hand, the mixing bulk and Knudsen diffusion is found for the diffusion barriers with pore size of $1.0,5.0$ and $10.0 \mu \mathrm{m}$. The different diffusion mechanism is mainly caused by the various pore sizes of the diffusion barriers (PTFE films). With the decrease in the pore size of the diffusion barrier, the contribution from Knudsen diffusion increases.

\subsection{Selectivity of NO gas sensor}

\subsubsection{Effect of humidity}

The inlet gas is moisturized by passage through two vessels connected in series which contained one of the following saturated solutions: $\mathrm{LiCl}(22 \%), \mathrm{Zn}\left(\mathrm{NO}_{3}\right)_{2}$ (49\%), $\mathrm{Mg}\left(\mathrm{NO}_{3}\right)_{2}(61 \%), \mathrm{NaCl}(82 \%)$ or pure water $(100 \%)$, the numbers in the parentheses specifying the corresponding relative humidity $(\mathrm{RH})$ measured by the wet-bubble thermometer. The humidity of inlet gas can be adjusted by mixing the various $\mathrm{RH}$ gases. Using $0.2 \mu \mathrm{m}$ pore size of PTFE film as diffusion barrier, the effect of humidity on the sensitivity of nitric oxide gas sensor is insignificant. The experimental results may be due to the hydrophobic property of PTFE film and/or the inactivity of water on the working electrode under these experimental conditions.

\subsubsection{Effect of oxygen}

The sensitivities of NO gas sensor evaluated from the slopes of the linear relationships in the Fig. 5 were 1.59, $1.42,1.46$ and $1.45 \mu \mathrm{A} \mathrm{ppm}^{-1}$, respectively, when the concentration of oxygen in the inlet gas are set to be 0,2500 , 5000 and $10000 \mathrm{ppm}$. The cathodic reduction of oxygen occurred at the potential less than $0.25 \mathrm{~V}$. The potential of $\mathrm{NO}$ gas sensor was operated at $1.05 \mathrm{~V}$ in this work. Therefore, the oxygen is inactive at this potential and the effect of oxygen on the sensitivity is slight.

\subsubsection{Effect of nitrogen dioxide}

The effect of concentration of $\mathrm{NO}$ on the limiting current of the $\mathrm{NO}$ gas sensor for various concentrations of $\mathrm{NO}_{2}$ was shown in Fig. 6. As the concentration of $\mathrm{NO}_{2}$ is changed, the sensitivity of NO gas sensor (slope of the linear relationship) changes slightly. On the other hand, the 


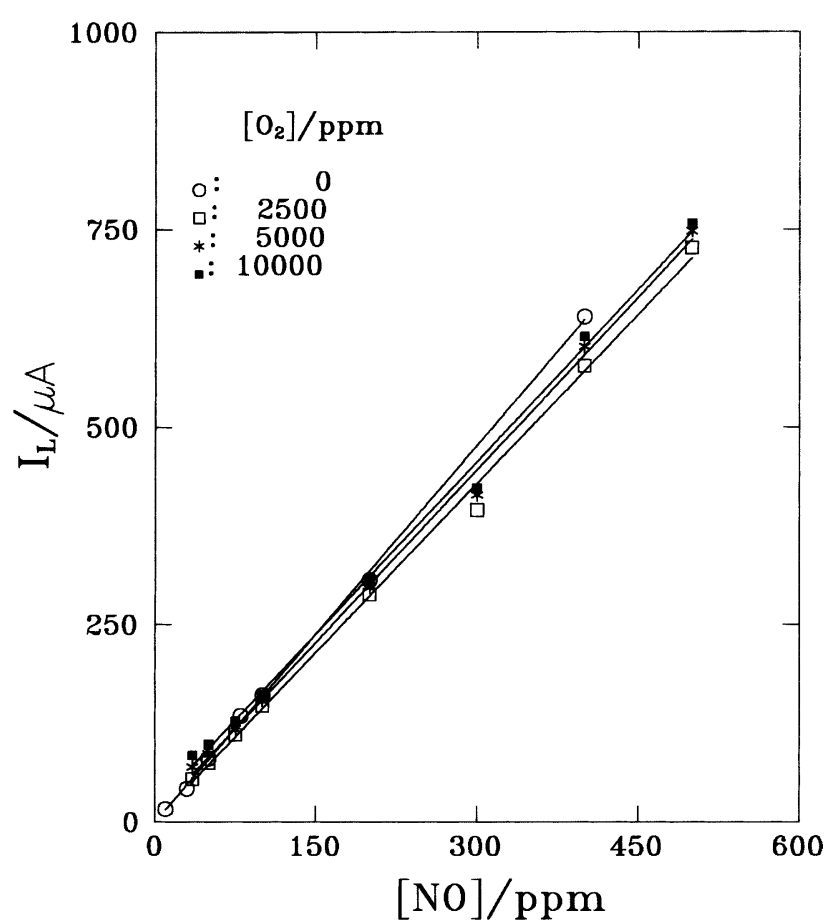

Fig. 5. Effect of the concentration of nitric oxide on the limiting current for various concentration of oxygen. Applied potential: $1.05 \mathrm{~V}$, room temperature, gas flow rate $=200 \mathrm{ml} \mathrm{min}^{-1}$, working electrode: $\mathrm{Au}$ / Nafion ${ }^{\circledR}$ (geometric area $=0.5 \mathrm{~cm}^{2}$, Au loading $=7.5 \mathrm{mg} / \mathrm{cm}^{2}$ ), diffusion barrier: $0.2 \mu \mathrm{m}$ pore size of PTFE film.

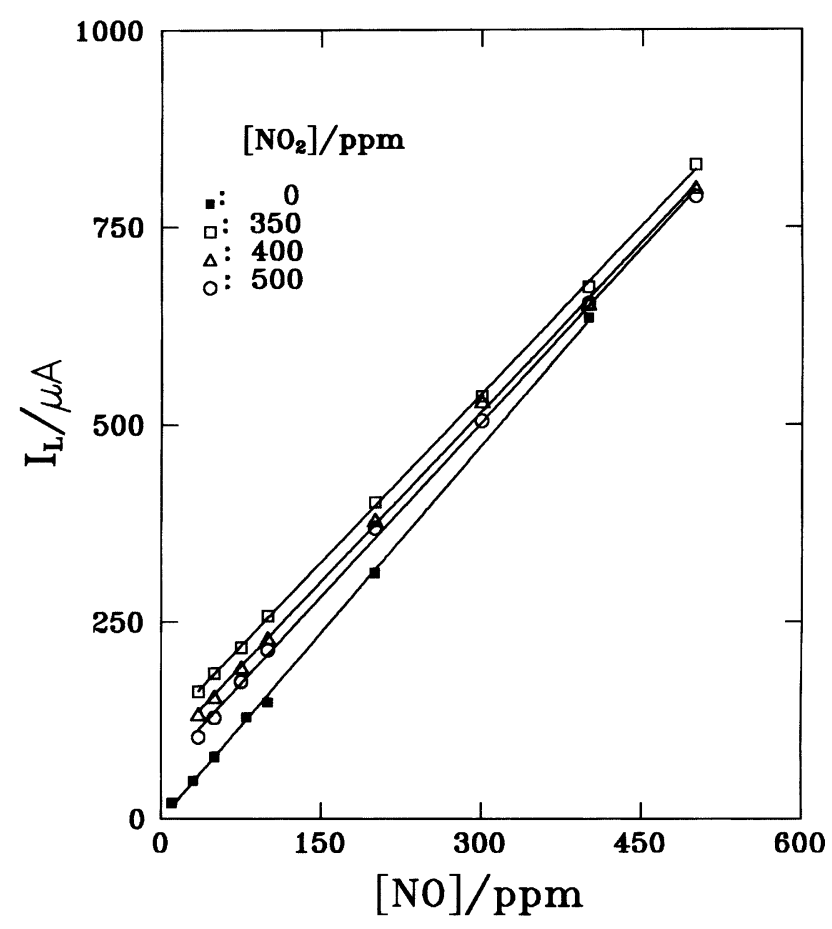

Fig. 6. Effect of the concentration of nitric oxide on the limiting current for various concentration of nitrogen dioxide. Applied potential: $1.05 \mathrm{~V}$, room temperature, gas flow rate $=200 \mathrm{ml} \mathrm{min}^{-1}$, working electrode: $\mathrm{Au}$ / Nafion ${ }^{\circledR}$ (geometric area $=0.5 \mathrm{~cm}^{2}$, Au loading $=7.5 \mathrm{mg} / \mathrm{cm}^{2}$ ), diffusion barrier: $0.2 \mu \mathrm{m}$ pore size of PTFE film.

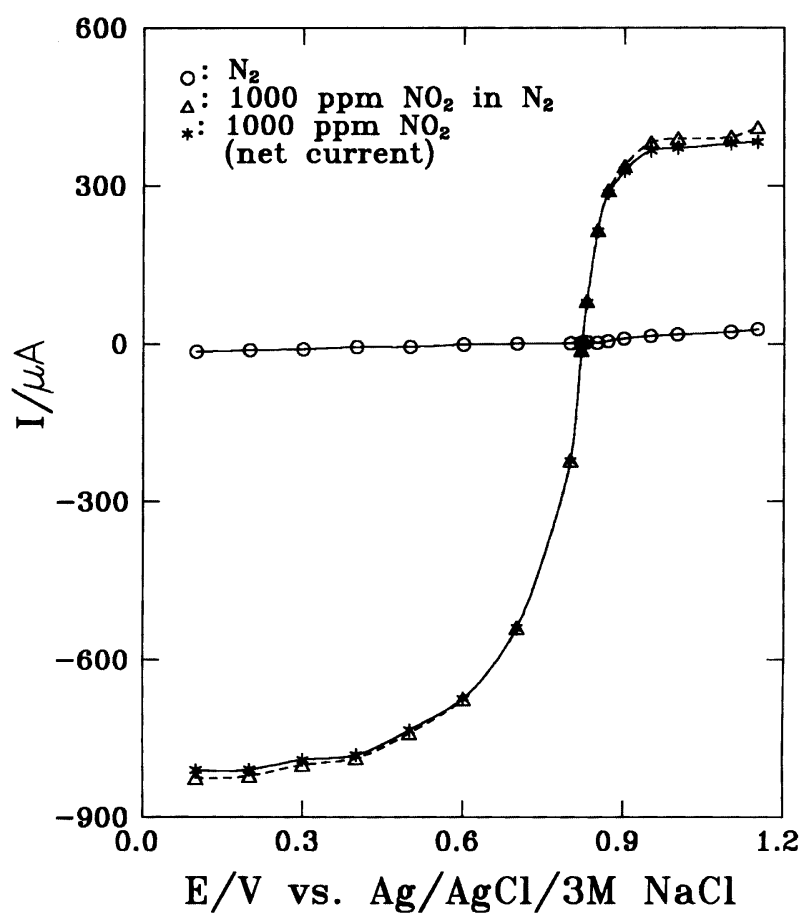

Fig. 7. $I-E$ curve of nitrogen dioxide. Gas flow rate $=200 \mathrm{ml} \mathrm{min}{ }^{-1}$, room temperature, working electrode: Au/Nafion ${ }^{\circledR}$ (geometric area $=0.5 \mathrm{~cm}^{2}$, Au loading $=7.5 \mathrm{mg} / \mathrm{cm}^{2}$ ), diffusion barrier: $0.2 \mu \mathrm{m}$ pore size of PTFE film.

intercepts of the lines in Fig. 6 increase from -0.3 to $113.0 \mu \mathrm{A}$ with the increase in the concentration of $\mathrm{NO}_{2}$ from 0 to $500 \mathrm{ppm}$.

Nitrogen dioxide is reduced on the cathode for the potential less than $0.83 \mathrm{~V}$ and the limiting current of the reduction of $\mathrm{NO}_{2}$ is obtained when the potential is less than $0.3 \mathrm{~V}$ (Fig. 7). Furthermore, nitrogen dioxide is oxidized for the potential greater than $0.83 \mathrm{~V}$ and the limiting current is found for the potential greater than $0.95 \mathrm{~V}$ (Fig. 7). The operating potential for $\mathrm{NO}$ gas sensor $(1.05 \mathrm{~V})$ is located in the region of the limiting current for oxidizing $\mathrm{NO}_{2}$. Hence, the increase in the intercept of the lines in Fig. 6 is caused by the oxidation of $\mathrm{NO}_{2}$ on the working electrode. The interference from the presence of $\mathrm{NO}_{2}$ can be reduced by passing inlet gas through triethanolamine to adsorb $\mathrm{NO}_{2}$ before the gas flows into the NO gas sensor [9].

\subsection{Effect of sulfur dioxide}

The current of anodic oxidation of sulfur dioxide increased from 13 to $2807 \mu \mathrm{A}$ with the increase of potential from 0.35 to $0.80 \mathrm{~V}$ as shown in Fig. 8. The limiting current is obtained for the potential greater than $0.80 \mathrm{~V}$. The potential applied in the NO gas sensor is overlapped with the potential for the limiting current of anodic oxidation of $\mathrm{SO}_{2}$. These results indicate that the sensitivity of $\mathrm{NO}$ gas sensor would be affected by the presence of sulfur dioxide in the inlet of gas. 


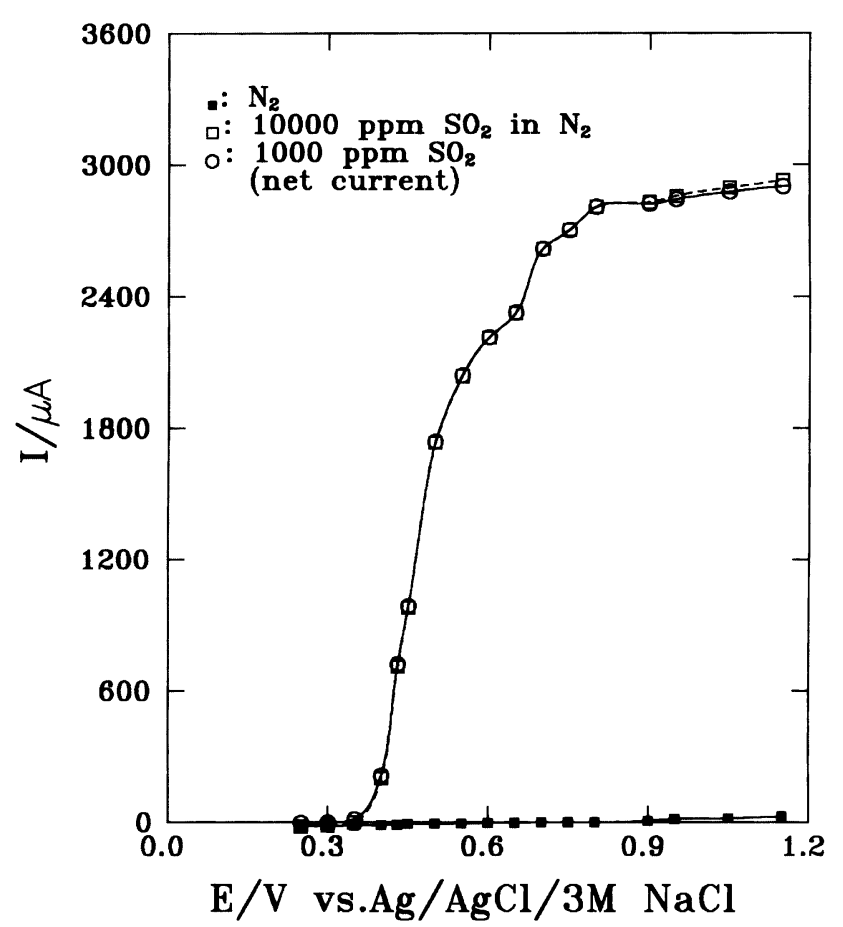

Fig. 8. $I-E$ curve of sulfur dioxide. Gas flow rate $=200 \mathrm{ml} \mathrm{min}^{-1}$, room temperature, working electrode: Au/Nafion ${ }^{\circledR}$ (geometric area $=0.5 \mathrm{~cm}^{2}$, Au loading $=7.5 \mathrm{mg} / \mathrm{cm}^{2}$ ), diffusion barrier: $0.2 \mu \mathrm{m}$ pore size of PTFE film.

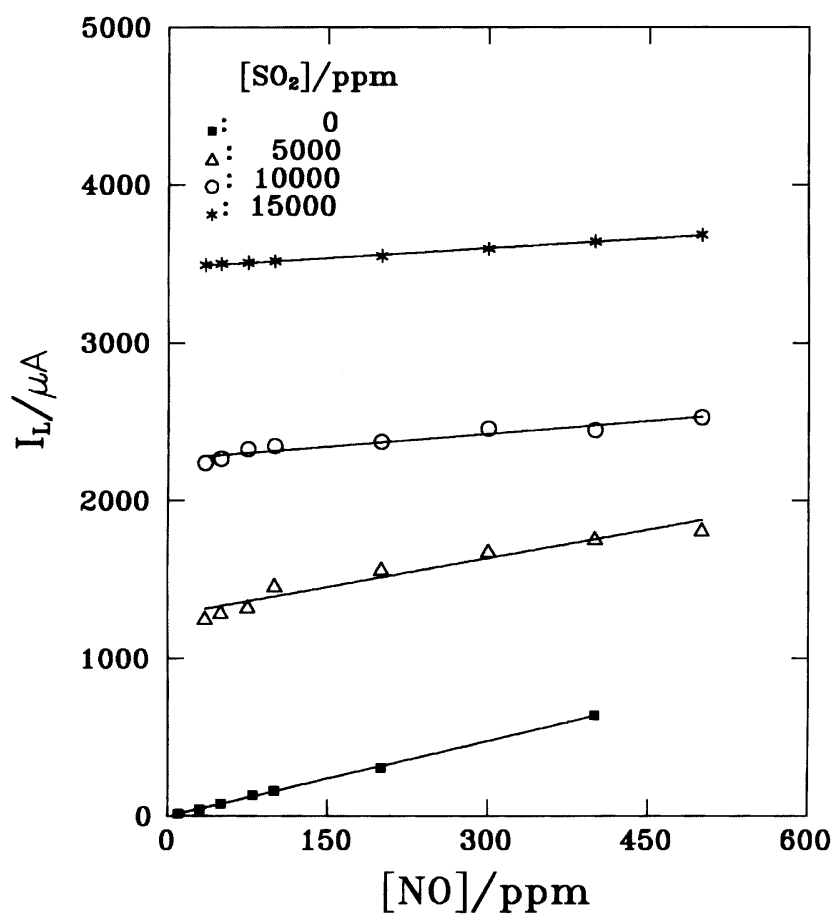

Fig. 9. Effect of the concentration of nitric oxide on the limiting current for various concentration of sulfur dioxide. Applied potential: $1.05 \mathrm{~V}$, room temperature, gas flow rate $=200 \mathrm{ml} \mathrm{min}-1$, working electrode: $\mathrm{Au} /$ Nafion ${ }^{\circledR}$ (geometric area $=0.5 \mathrm{~cm}^{2}$, Au loading $=7.5 \mathrm{mg} / \mathrm{cm}^{2}$ ), diffusion barrier: $0.2 \mu \mathrm{m}$ pore size of PTFE film.
Increasing the concentration of $\mathrm{SO}_{2}$ from 0 to $15000 \mathrm{ppm}$ resulted in the increase of the intercept of linear relationships in Fig. 9 from -0.3 to $3475 \mu \mathrm{A}$. The increase in the intercept is contributed by the anodic oxidation of $\mathrm{SO}_{2}$. In the meanwhile, the sensitivity of $\mathrm{NO}$ gas sensor decreased from 1.57 to $0.04 \mu \mathrm{A} \mathrm{ppm}^{-1}$ if the concentration of $\mathrm{SO}_{2}$ was increased from 0 to $15000 \mathrm{ppm}$. The experimental results reveal that the electrochemical activity is affected by the presence of $\mathrm{SO}_{2}$. The interference from the presence of $\mathrm{SO}_{2}$ can be reduced by the adsorption of $\mathrm{SO}_{2}$ for passing inlet of gas through mercuric salts before the gas flows into the NO gas sensor [9].

\subsubsection{Effect of carbon monoxide}

The sensitivity of NO gas sensor decreased slightly from 1.56 to $1.47 \mu \mathrm{A} \mathrm{ppm}^{-1}$ with the increase in concentration of $\mathrm{CO}$ from 0 to $20000 \mathrm{ppm}$ in the gas inlet. The experimental results indicate that the anodic oxidation of carbon monoxide is insignificant for the potential applied in the amperometric NO gas sensor. The interference from carbon monoxide in the NO gas sensor can be neglected.

\section{Conclusions}

The mass transfer of nitric oxide in the amperometric NO gas sensor in the presence of diffusion barrier is theoretically and experimentally discussed. The mass transfer resistance in the gas diffusion layer can be neglected and the effect of the gas flow rate on the sensitivity of NO gas sensor is insignificant in the presence of diffusion barrier for the gas flow rate greater than $160 \mathrm{ml} \mathrm{min}^{-1}$. For the gas flow rate greater than $160 \mathrm{ml} \mathrm{min}^{-1}$, the sensitivity of $\mathrm{NO}$ gas sensor changes slightly due to the similar mass transfer resistance found in the various pore size and thickness of PTFE diffusion barriers. The diffusion coefficients of nitric oxide in the diffusion barrier with pore size of $0.2,1.0,5.0$ and $10.0 \mu \mathrm{m}$ are found from the theoretical analysis and experimental data to be $8.57 \times 10^{-6}, 1.00 \times 10^{-5}, 1.33 \times 10^{-5}$ and $1.45 \times 10^{-5} \mathrm{~cm}^{2} \mathrm{~s}^{-1}$, respectively. The effect of temperature on the diffusion of nitric oxide in the diffusion barrier indicates that the contribution from Knudsen diffusion increases with the decrease in the pore size of diffusion barrier. The interference from humidity, oxygen and carbon monoxide is experimentally found to be insignificant in the amperometric nitric oxide gas sensor. The significant interference found in the NO gas sensor for the presence of nitrogen dioxide and sulfur dioxide are mainly contributed from the anodic oxidation of interfering gases $\left(\mathrm{NO}_{2}\right.$ and $\mathrm{SO}_{2}$ ) on the working electrode.

\section{Acknowledgements}

The support of National Science Council of the Republic of China (NSC 85-2214-E-029-003) is acknowledged. 


\section{References}

[1] A. Fontijn, A.J. Sabadell, R.J. Ronco, Homogeneous chemiluminescent measurement of nitric oxide with ozone, Anal. Chem. 42 (1970) 575-579.

[2] S.C. Chang, D.B. Hicks, Tin Oxide Microsensors, Fundamentals and Applications of Chemical Sensor, Maple Press, New York, PA, 1986.

[3] T. Ishihara, K. Shiokawa, K. Eguchi, H. Arai, The mixed oxide $\mathrm{Al}_{2} \mathrm{O}_{3}-\mathrm{V}_{2} \mathrm{O}_{5}$ as a semiconductor gas sensor for $\mathrm{NO}$ and $\mathrm{NO}_{2}$, Sens. Actuators 19 (1989) 259-265.

[4] N. Rao, C.M. Bleek, J. Schoonman, Potentiometric $\mathrm{NO}_{x}$ sensor with alumina as solid electrolyte and Ag metal as solid reference, Solid State Ionics 52 (1992) 339-346.

[5] K.F. Blurton, J.M. Sedlak, Device for the detection and measurement of $\mathrm{NO}$ and $\mathrm{NO}_{2}$ gases, US Patent 4,001,103 (1977).

[6] K.F. Blurton, J.M. Sedlak, Device for the detection and measurement of $\mathrm{NO}$ and $\mathrm{NO}_{2}$ gases, US Patent 4,042,464 (1977).

[7] K.F. Blurton, J.M. Sedlak, Device for the detection and measurement of $\mathrm{NO}$ and $\mathrm{NO}_{2}$ gases, US Patent 4,052,268 (1977).

[8] J.M. Sedlak, K.F. Blurton, The electrochemical reaction of carbon monoxide, nitric oxide, and nitrogen dioxide at gold electrode, J. Electrochem. Soc. 123 (1976) 1476-1478.

[9] J.M. Sedlak, K.F. Blurton, A new electrochemical analyser for nitric oxide and nitrogen dioxide, Talanta 23 (1976) 811-814.

[10] G.J. Maclay, W.J. Buttner, J.R. Stetter, Microfabricated amperometric gas sensors, IEEE Trans. Electron Devices 35 (1988) 793799.

[11] W.J. Buttner, G.J. Maclay, J.R. Stetter, An integrated amperometric microsensor, Sens. Actuators 1 (1990) 303-307.

[12] F. Maseeh, M.J. Tierney, W.S. Chu, J. Joseph, H.-O.L. Kim, T. Otagawa, A novel silicon micro amperometric gas sensor, in:
Proceedings of the International Conference on Solid State Sensors and Actuators, Transducers'91, San Francisco, CA, 1991, pp. 359362 .

[13] F. Opekar, K. Stulik, Electrochemical sensors with solid polymer electrolytes, Anal. Chim. Acta 385 (1999) 151-162.

[14] G. Harsanyi, Polymer Films in Sensor Applications: Technology, Materials, Devices and Their Characteristics, Technomic Publishing, Lancaster, 1995.

[15] F. Ménil, V. Coillard, C. Lucat, Critical review of nitrogen monoxide sensors for exhaust gases of lean burn engines, Sens. Actuators 67 (2000) 1-23.

[16] J.S. Do, K.J. Wu, Amperometric nitric oxide gas sensor: preparation of Au/SPE and sensing behavior, Sens. Actuators 67 (2000) 209-216.

[17] J.S. Do, K.J. Wu, Amperometric nitric oxide gas sensor based on solid polymer electrolyte: kinetics and mass transfer, J. Appl. Electrochem. 31 (2001) 437-443.

[18] J.S. Do, R.Y. Shieh, Electrochemical nitrogen dioxide gas sensor based on solid polymeric electrolyte, Sens. Actuators 37 (1996) 1926.

[19] H. Schlichting, Boundary Layer Theory, McGraw-Hill, New York, 1955, pp. 204-206.

[20] R. Bauer, D.K. Friday, D.J. Kirwan, Mass transfer and kinetics effects in an electron-driven homogeneous reaction, Ind. Eng. Chem. Fundam. 20 (1981) 141-147.

[21] T.C. Chou, J.S. Do, B.J. Hwang, J.J. Jow, The roles of redox mediators in the anodic oxidation of glucose, Chem. Eng. Commun. 51 (1987) 47-62.

[22] A.J. Bard, L.R. Faulkner, Electrochemical Methods: Fundamentals and Applications, Wiley, New York, 1980, p. 143.

[23] A.L. Hines, R.N. Maddox, Mass Transfer Fundamentals and Applications, Prentice-Hall, Englewood Cliffs, NJ, 1985. 